\title{
Desempenho e qualidade do ovo de codornas japonesas alimentadas com rações contendo sorgo
}

\author{
Adolpho Marlon Antoniol de Moura ${ }^{1}$, José Brandão Fonseca ${ }^{2}$, Carlos Bôa-Viagem Rabello ${ }^{3}$, \\ Fátima Naomi Takata ${ }^{4}$, Newton Tavares Escocard de Oliveira ${ }^{5}$ \\ ${ }^{1}$ Centro de Pesquisas Aggeu Magalhães - CPqAM/Fiocruz. Av. Moraes Rego, s/n, Cidade Universitária, Recife, PE, CEP: 50670-420; \\ Programa de Pós-graduação em Ciência Animal da Universidade Estadual do Norte Fluminense Darcy Ribeiro/UENF. \\ 2 LZNA/CCTA - Universidade Estadual do Norte Fluminense Darcy Ribeiro. \\ ${ }^{3}$ Departamento de Zootecnia - Universidade Federal Rural de Pernambuco. \\ 4 Departamento de Morfologia e Fisiologia Animal - Universidade Federal Rural de Pernambuco. \\ ${ }^{5}$ Centro de Ciências Agrárias - Universidade Estadual do Oeste do Paraná.
}

RESUMO - Objetivou-se com este estudo avaliar o desempenho e a qualidade dos ovos de codornas japonesas (Coturnix japonica) alimentadas com rações cotendo sorgo de baixo tanino em substituição ao milho. Foram utilizadas 210 codornas japonesas fêmeas com 65 dias de idade, distribuídas em delineamento inteiramente casualizado com cinco rações experimentais $(0 ; 25 ; 50 ; 75$ e $100 \%$ de sorgo em substituição ao milho) e seis repetições de sete aves. No experimento, cuja duração foi de 112 dias, não houve efeito significativo dos níveis de sorgo nas rações sobre nenhuma das características de produção. Com aumento dos níveis de sorgo na ração, houve redução linear da cor da gema e do custo da ração. O sorgo de baixo tanino pode substituir totalmente o milho em rações para codornas japonesas em postura.

Palavras-chave: alimento alternativo, cor da gema, coturnix, produção de ovos

\section{Performance and egg quality of laying Japanese quails fed rations with different sorghum levels}

\begin{abstract}
The aim of this study was to evaluate performance and egg quality of Japanese quails (Coturnix japonica) fed rations with low-tannin sorghum replacing corn. Two hundred and ten $65-\mathrm{d}$ female Japanese quails were distributed in a complete random design with five experimental rations $(0,25,50,75$ and $100 \%$ replacement of corn by sorghum) and six replicates with seven birds. There was no significant effect of sorghum levels in the diets on any of the production characteristics in this experiment, which lasted for 112 days. As the levels of sorghum in the ration increased, yolk color and ration cost were reduced. Low-tannin sorghum can completely replace corn in rations for laying Japanese quails.
\end{abstract}

Key Words: alternative ingredients, coturnix, egg production, yolk color

\section{Introdução}

A coturnicultura é uma atividade avícola em expansão, responsável pela geração de emprego e renda em todos os níveis de sua cadeia produtiva. Além disso, seu principal produto, o ovo, é uma fonte de proteína animal de alto valor biológico.

Empresas têm investido na modernização de instalações, qualificação de mão-de-obra, melhoramento genético das linhagens e em formulações de rações mais adequadas ao potencial produtivo da espécie (Moura et al., 2008).

As pesquisas em nutrição de codornas têm sido direcionadas principalmente para determinação das exigências nutricionais e avaliação de alimentos para as linhagens de postura e corte. Os alimentos não-convencionais têm sido foco crescente dessas pesquisas, uma vez que não competem com a alimentação humana ou são descartados pelas agroindústrias (potenciais poluentes ambientais) e de custo inferior ao dos alimentos convencionais.

O principal ingrediente que compõe as rações das aves é o milho, que determina 60 a $70 \%$ do custo das formulações. Por se tratar de uma commoditie, seu preço está sujeito às variações cambiais e cotações de mercado, o que pode ocasionar desequilíbrio na oferta interna do insumo e alterar a estratégia de compra pelos produtores, que buscam reduzir os custos e aumentar os lucros.

Para as atividades pecuárias, altamente dependentes desse insumo, têm se buscado ingredientes não- 
convencionais para sua substituição parcial ou total. Segundo Scheuermann (2003), entre as opções pesquisadas, aquela que mais se aproxima das características nutricionais do milho é o sorgo (Sorghum bicolor, L. Moench).

O custo do sorgo situa-se entre 70 e $80 \%$ do valor do milho e tecnicamente pode substituir até $100 \%$ do milho em rações para frangos de corte (Rocha et al., 2008) e poedeiras (Assuena et al., 2008) sem prejudicar o desempenho dessas aves. Todavia, recomenda-se a inclusão de pigmentantes na ração, uma vez que o sorgo é pobre em carotenoides (Silva et al., 2000).

Faquinello et al. (2004) avaliaram a substituição do milho pelo sorgo alto tanino para codornas japonesas e concluíram que é viável a substituição de até $80 \%$, embora tenham notado piora na conversão alimentar, taxa de postura e cor da gema com aumento dos níveis de sorgo na ração.

Objetivou-se avaliar o efeito da substituição do milho pelo sorgo baixo tanino sobre o desempenho e a qualidade dos ovos de codornas japonesas em postura.

\section{Material e Métodos}

O experimento teve duração de 112 dias e foi realizado no Laboratório de Laboratório de Digestibilidade de Nãoruminantes do Departamento de Zootecnia da Universidade Federal Rural de Pernambuco (UFRPE). Foram utilizadas 210 codornas japonesas, linhagem Fujikura (Coturnix japonica,Temminck \& Schlegel, 1849), com 65 dias de idade, $160,97 \pm 7,90 \mathrm{~g}$ de peso vivo e taxa de produção de ovos inicial de $85 \% \pm 3,87 \%$, devidamente vacinadas contra marek, gumboro, new castle e bouba aviária.

As codornas foram distribuídas em delineamento inteiramente casualizado, com cinco rações experimentais, formuladas substituindo $0 ; 25 ; 50 ; 75$ e $100 \%$ do milho por sorgo de baixo tanino nos níveis de contendo seis repetições e sete aves por unidade experimental, previamente uniformizadas pelo peso corporal e produção de ovos.

A distribuição das aves foi feita em 30 gaiolas de arame galvanizado dispostas em cinco andares com seis gaiolas por andar, com dimensão de $33 \mathrm{~cm}$ de comprimento $\times 25 \mathrm{~cm}$ de largura $\times 20 \mathrm{~cm}$ de altura, fornecendo $117 \mathrm{~cm}^{2} /$ ave, compostas de comedouros e bebedouros do tipo calha, além de aparador de excretas posicionado abaixo das gaiolas.

A água e a ração foram disponibilizadas à vontade e fornecidas duas vezes ao dia. Foi utilizado o programa de iluminação com fotoperíodo diário de 17 horas de luz, com lâmpadas fluorescentes dispostas no galpão, de modo a evitar sombreamento de comedouros e controladas por um relógio automático temporizado (timer). As temperaturas mínima e máxima e a umidade relativa do ar no interior do galpão foram registradas três vezes ao dia (às $8 \mathrm{~h}, 13 \mathrm{~h} \mathrm{e}$ $18 \mathrm{~h}$ ) por termômetros de amplitude e de psicrômetro, distribuídos em diferentes pontos do galpão e posicionados à altura das aves. Ao final do experimento foram calculados os dados médios diários para cada variável ambiental em estudo.

As rações experimentais foram formuladas à base de milho e/ou sorgo de baixo tanino (cultivar IPA 7301011) e farelo de soja e foram isonutritivas (Tabela 1). Para compor as rações utilizou-se o software SuperCrac 5.0. a partir das exigências nutricionais para codornas japonesas em postura, descritas pelo National Research Council (NRC, 1994), exceto para proteína bruta e cálcio, para os quais foram utilizadas as recomendações de Oliveira et al. (1999) e Barreto et al. (2007), respectivamente.

Utilizou-se para formular as rações os valores de energia metabolizável aparente corrigida pelo balanço de nitrogênio (EMn), em quilocaloria por quilograma de matéria natural, do milho (3.572), sorgo (3.108), farelo de soja (2.633) e óleo de soja refinado (9.335), determinados previamente em ensaio de metabolismo com codornas japonesas fêmeas com 60 a 67 dias de idade, realizado por Moura et al. (2010).

Os valores de proteína bruta do milho $(8,38 \%)$, sorgo $(10,99 \%)$ e farelo de soja $(45,00 \%)$ foram determinados no Laboratório de Zootecnia e Nutrição Animal da Universidade Estadual do Norte Fluminense Darcy Ribeiro, utilizando a metodologia descrita por Silva \& Queiroz (2002). Para os demais nutrientes, foram utilizados os dados de composições dos ingredientes descritas por Rostagno et al. (2005).

As rações experimentais de cada repetição foram acondicionadas em sacos plásticos devidamente identificados e o consumo foi calculado ao término de cada semana, por meio da diferença entre a quantidade de ração fornecida e as sobras.

Foram avaliadas as características de desempenho: peso final das aves (g), produção média de ovos por ave/dia (\%), consumo de ração (g/ave/dia), peso dos ovos (g), massa de ovos (g de ovo/ave/dia) e a conversão alimentar ( $\mathrm{g}$ de ração por massa de ovo e por dúzia de ovos). As variáveis de qualidade dos ovos foram peso da gema (g), peso do albúmen $(\mathrm{g})$, peso da casca $(\mathrm{g})$, espessura da casca $(\mu \mathrm{m}) \mathrm{e}$ cor da gema (escore colorimétrico e colorimetria por refletância). Para cálculo do custo das rações experimentais, foram considerados os preços médios $(\mathrm{R} \$)$ dos insumos comercializados no município de Recife, Pernambuco, à época do experimento.

A coleta dos ovos foi realizada diariamente, pela manhã, e a produção média de ovos foi obtida dividindo-se o total de ovos produzidos (ovos inteiros, quebrados, trincados e deformados) pelo número de aves viáveis de 
Tabela 1 - Composição percentual e nutricional das rações experimentais

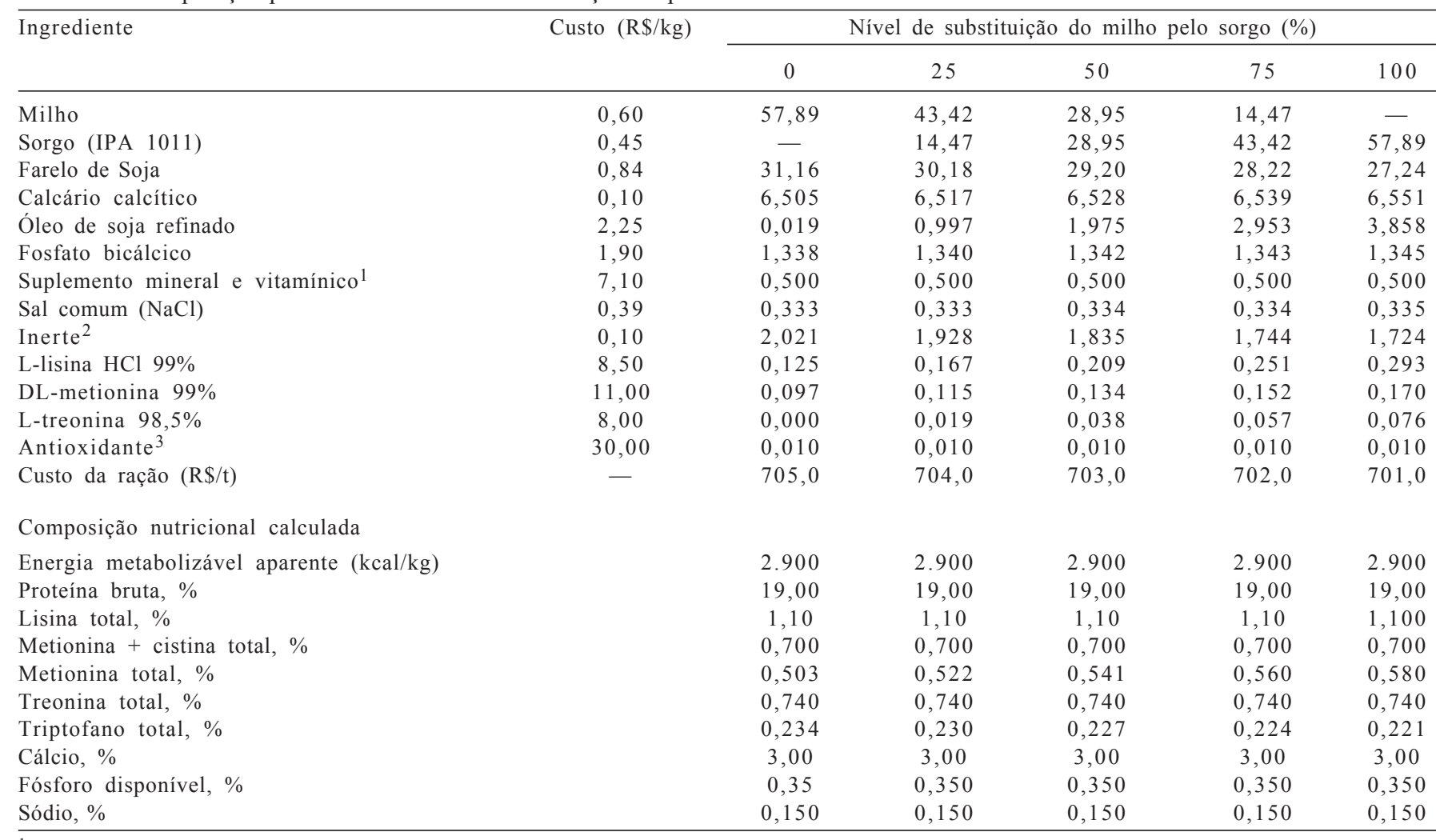

${ }^{1}$ Níveis de garantia (por quilo do produto): metionina - $218000 \mathrm{mg}$; cianocobalamina - $10000 \mathrm{mcg}$; ácido fólico - $400 \mathrm{mg}$; pantotenato de cálcio - $3000 \mathrm{mg}$; biotina - $10 \mathrm{mg}$; colina - $126.000 \mathrm{mg}$; niacina - $7000 \mathrm{mg}$; piridoxina - $800 \mathrm{mg}$; tiamina - $800 \mathrm{mg}$; riboflavina - $1200 \mathrm{mg}$; menadiona - $500 \mathrm{mg}$; vit. A - 2.000.000 UI; vit. D3 - 50.000 UI; vit. E - $10.000 \mathrm{UI}$; Cu - $2.000 \mathrm{mg}$; Fe - $16.000 \mathrm{mg}$; I - $200 \mathrm{mg}$; Mn - $18.000 \mathrm{mg} ; \mathrm{Zn}-14.000 \mathrm{mg}$; Se - $10.000 \mathrm{mcg}$.

2 Areia lavada.

${ }^{3}$ Butil-hidroxitolueno.

cada parcela. A conversão alimentar, dividindo-se o total de ração consumida pelo peso dos ovos produzidos, sendo expressa em gramas de ração por grama de ovo produzido. A conversão alimentar por dúzia de ovos foi obtida pelo produto entre o consumo médio de ração e a dúzia de ovos produzidos. Com o peso total e o número de ovos por parcela, foi calculado o peso médio dos ovos das parcelas. A viabilidade das aves foi calculada pela subtração do número de aves alojadas no início do experimento pela mortalidade, em valor percentual.

Para determinação do peso de gema, albúmen e casca e da espessura da casca, foram coletados aleatoriamente, a cada 28 dias, cinco ovos íntegros de cada parcela durante três dias consecutivos. Após a identificação e pesagem em balança com precisão de $0,01 \mathrm{~g}$, os ovos foram quebrados e suas gemas separadas manualmente e pesadas. As cascas foram secas em estufa de ventilação forçada por 24 horas a $105^{\circ} \mathrm{C}$ e novamente pesadas. O peso do albúmen foi obtido pela diferença entre o peso do ovo e dos pesos da casca e da gema.

A espessura de casca, incluindo as membranas, foi medida por meio da leitura em quatro pontos distintos na região equatorial utilizando-se um micrometro externo marca Mitutoyo modelo 103-137 com curso de $25 \mathrm{~mm}$, leitura de $0,01 \mathrm{~mm}$ e precisão de $0,002 \mathrm{~mm}$. A espessura foi obtida pelo valor médio das quatro medições, segundo metodologia descrita por Nordstrom \& Ousterhout (1982).

A análise da cor da gema foi realizada no Laboratório de análises físico-químicas de alimentos do Departamento de Ciências Domésticas da UFRPE, utilizando-se quatro gemas por repetição e duas metodologias, sendo uma subjetiva e a outra direta (instrumental).

Na primeira, utilizou-se o escore colorimétrico $\operatorname{DSM}^{\circledR}$ (leque ou abanico), na qual a cor da gema foi comparada a uma escala de cores do abanico, e de acordo com a semelhança visual, obtida por três avaliadores, foi atribuído um valor médio entre um e 15 , conforme descrito por Galobart et al. (2004).

Para o método direto de caracterização cromática, foi utilizado a colorimetria de triestímulos, no sistema CIELAB, por meio do colorímetro Minolta CR 400 (Konica Minolta Sensing, Inc.) no modo de reflectância, utilizando iluminação difusa, iluminante $\mathrm{C}$ (tipo de fonte de luz que representa a média da luz de dia, com temperatura de cor de $6740^{\circ} \mathrm{K}$ ) e os ângulos de $0^{\circ}$ e de $2^{\circ}$, referentes aos ângulos de detecção e do observador, respectivamente. 
No sistema de cores CIELAB utiliza-se três coordenadas do croma $\left(L^{*}, a^{*} e b^{*}\right)$ para descrever o padrão cromático da gema. O valor de $L^{*}$ define os valores de luminosidade, que varia do preto $(\mathrm{L}=0)$ ao branco $(\mathrm{L}=100) ; a^{*}$ indica a região do vermelho $(+\mathrm{a})$ ao verde (-a) e o $b^{*}$ do amarelo (+b) ao azul (-b).

Como o milho é a principal fonte de pigmento amarelo em rações comerciais de aves, optou-se pela avaliação apenas da coordenada $b^{*}$, que caracteriza a faixa de cor do amarelo, atendendo precisamente aos objetivos propostos.

O colorímetro foi previamente calibrado em superfície branca, de acordo com padrões pré-estabelecidos por Bible \& Singha (1997). Após esse procedimento, quatro gemas de cada repetição foram homogeneizadas (pool) e colocadas em placa de Petri de vidro sobreposta em placa branca. Para cada repetição, o registro das coordenadas de cor foi realizado em cinco diferentes pontos da placa contendo as gemas, cujos resultados foram expressos como a média dos cinco registros da coordenada de cor $b^{*}$.

A normalidade dos dados das variáveis foi verificada por meio do teste de Lilliefors, a $5 \%$ de probabilidade. Os efeitos dos níveis de substituição do milho pelo sorgo foram avaliados pela análise de variância a $5 \%$ de probabilidade. Posteriormente, realizou-se análise de regressão dos dados das características em cada nível de substituição do milho pelo sorgo. Todas as análises foram realizadas utilizando-se a versão 9.1 do Sistema de análises estatísticas e genéticas - SAEG (UFV, 2007).

\section{Resultados e Discussão}

As médias das temperaturas mínima e máxima e a umidade relativa do ar registradas diariamente durante o período experimental foram, respectivamente, $24,2^{\circ} \mathrm{C} \pm 1,63 ; 30$, $7^{\circ} \mathrm{C} \pm 1,30^{\circ} \mathrm{C}$ e $81,4 \pm 5,74 \%$, com uma amplitude térmica diária de $\pm 6,5^{\circ} \mathrm{C}$ de temperatura e $11,2 \%$ de umidade relativa do ar dentro do galpão experimental.

Não houve efeito significativo da substituição do milho pelo sorgo baixo tanino sobre nenhuma das características de desempenho (Tabela 2). Os resultados confirmam a compatibilidade nutricional do sorgo com o milho e evidenciam seu potencial para uso integral na alimentação de codornas em postura. Além do perfil nutricional equivalente ao do milho, a cultivar de sorgo avaliada (IPA 1011) é uma variedade de baixo tanino.

Não foram encontrados possíveis efeitos antinutricionais causados pela possível presença de compostos fenólicos, fato compatível com relatos de Faquinello et al. (2004), que recomendaram a substituição de no máximo $80 \%$ do milho pelo sorgo com alto tanino para máximo desempenho de codornas japonesas em postura.

Tabela 2 - Desempenho de codornas japonesas alimentadas com rações contendo sorgo em substituição milho

\begin{tabular}{|c|c|c|c|c|c|c|}
\hline \multirow[t]{2}{*}{ Variável } & \multicolumn{5}{|c|}{ Nível de substituição do milho pelo sorgo (\%) } & \multirow[t]{2}{*}{ CV $(\%$} \\
\hline & 0 & 20 & 50 & 75 & 100 & \\
\hline Peso das aves $(\mathrm{g})^{\mathrm{NS}}$ & $181,3 \pm 9,4$ & $179,4 \pm 6,2$ & $182,3 \pm 10,9$ & $182,4 \pm 8,9$ & $182,6 \pm 10,8$ & 5,21 \\
\hline Produção de ovos $(\%)^{\mathrm{NS}}$ & $93,3 \pm 6,7$ & $90,1 \pm 6,0$ & $90,6 \pm 9,9$ & $90,4 \pm 5,9$ & $93,3 \pm 2,5$ & 7,39 \\
\hline Peso dos ovos $(\mathrm{g})^{\mathrm{NS}}$ & $11,9 \pm 0,2$ & $11,6 \pm 0,5$ & $11,7 \pm 0,4$ & $11,8 \pm 0,1$ & $11,8 \pm 0,5$ & 3,23 \\
\hline Massa de ovos $(\mathrm{g} \text { ovo/ave/dia })^{\mathrm{NS}}$ & $11,10 \pm 0,9$ & $10,45 \pm 0,8$ & $10,60 \pm 0,7$ & $10,67 \pm 0,8$ & $11,01 \pm 0,6$ & 8,68 \\
\hline Consumo de ração (g/ave/dia) ${ }^{\mathrm{NS}}$ & $28,5 \pm 1,3$ & $28,4 \pm 1,5$ & $27,9 \pm 1,7$ & $27,6 \pm 1,6$ & $28,2 \pm 1,6$ & 5,64 \\
\hline C.A. por massa de ovo (g ração/g ovo $)^{\mathrm{NS}}$ & $3,65 \pm 0,35$ & $3,64 \pm 0,45$ & $3,62 \pm 0,35$ & $3,63 \pm 0,24$ & $3,57 \pm 0,36$ & 9,75 \\
\hline C.A. por dúzia de ovos (g ração/dúzia) ${ }^{\mathrm{NS}}$ & $362,2 \pm 32,5$ & $358,2 \pm 3,8$ & $365,2 \pm 29,7$ & $359,6 \pm 18,3$ & $361,8 \pm 20,9$ & 6,58 \\
\hline Viabilidade $(\%)^{\mathrm{NS}}$ & 91,74 & 90,82 & 91,04 & 90,10 & 92,00 & 6,77 \\
\hline
\end{tabular}

NS - Não-significativo (P>0,05); CV - Coeficiente de variação; CA - Conversão alimentar.

Tabela 3 - Qualidade do ovo de codornas japonesas alimentadas com rações contendo sorgo em substituição ao milho

\begin{tabular}{|c|c|c|c|c|c|c|}
\hline \multirow[t]{2}{*}{ Item } & \multicolumn{5}{|c|}{ Nível de substituição do milho pelo sorgo (\%) } & \multirow[t]{2}{*}{ CV $(\%$} \\
\hline & 0 & 20 & 50 & 75 & 100 & \\
\hline Peso do ovo (g) & $11,99 \pm 0,21$ & $11,63 \pm 0,53$ & $11,76 \pm 0,40$ & $12,02 \pm 0,17$ & $11,72 \pm 0,54$ & 3,47 \\
\hline Peso da gema (g) & $3,82 \pm 0,23$ & $3,63 \pm 0,18$ & $3,64 \pm 0,20$ & $3,78 \pm 0,16$ & $3,69 \pm 0,29$ & 5,85 \\
\hline Peso do albúmen $(\mathrm{g})$ & $7,27 \pm 0,25$ & $7,08 \pm 0,23$ & $7,20 \pm 0,55$ & $7,26 \pm 0,13$ & $7,07 \pm 0,44$ & 4,93 \\
\hline Peso da casca $(\mathrm{g})$ & $0,90 \pm 0,05$ & $0,92 \pm 0,04$ & $0,92 \pm 0,07$ & $0,98 \pm 0,05$ & $0,96 \pm 0,08$ & 6,56 \\
\hline Espessura da casca $(\mu \mathrm{m})$ & $255 \pm 21$ & $263 \pm 11$ & $261 \pm 10$ & $259 \pm 74$ & $265 \pm 13$ & 5,11 \\
\hline Cor da gema (leque DSM) ${ }^{* *} \mathrm{~L}$ & $7,21 \pm 0,33$ & $6,52 \pm 0,54$ & $5,56 \pm 0,44$ & $3,88 \pm 0,22$ & $1,48 \pm 0,27$ & 7,70 \\
\hline Cor da gema $\left(\text { Valor } b^{*}\right)^{* * \mathrm{~L}}$ & $30,17 \pm 0,63$ & $30,99 \pm 1,51$ & $29,50 \pm 0,55$ & $24,46 \pm 3,40$ & $19,50 \pm 3,02$ & 8,08 \\
\hline
\end{tabular}

CV - Coeficiente de variação; $*$ L Efeito para regressão linear $(\mathrm{p}<0,01)$. 
A substituição total do milho pelo sorgo em rações para galinhas poedeiras foi recomendada por Moreno et al. (2007) e Assuena et al. (2008), que observaram desempenho equivalente entre as aves alimentadas com rações contendo diferentes proporções de milho ou sorgo contendo baixo tanino.

A substituição do milho pelo sorgo também não teve efeito $(\mathrm{P}>0,05)$ sobre as características de qualidade do ovo, como peso da gema, do albúmen, da casca e da espessura de casca (Tabela 3). Entretanto, houve efeito para coloração da gema, independentemente do método de avaliação (escore colorimétrico DSM e colorimetria por refletância).

A cor da gema reduziu de forma linear de acordo com o aumento dos níveis de sorgo na ração e essa redução podendo ser representada pelas equações $\hat{Y}=7,750-$ $0,05642 \mathrm{X}\left(\mathrm{r}^{2}=0,91\right)$, e $\hat{\mathrm{Y}}=32,497-0,1115 \mathrm{X}\left(\mathrm{r}^{2}=0,68\right)$, obtidas pelo escore colorimétrico e por colorimetria, respectivamente. As equações demonstraram que, a cada $1 \%$ de inclusão de sorgo, houve diminuição de 0,056 no escore de cor e 0,112 pela colorimetria de refletância.

Segundo Silva et al. (2000), a inclusão de sorgo na ração têm como consequência direta a redução na coloração da gema. Esse efeito foi observado com a redução linear na coloração geral da gema, avaliada por meio do escore
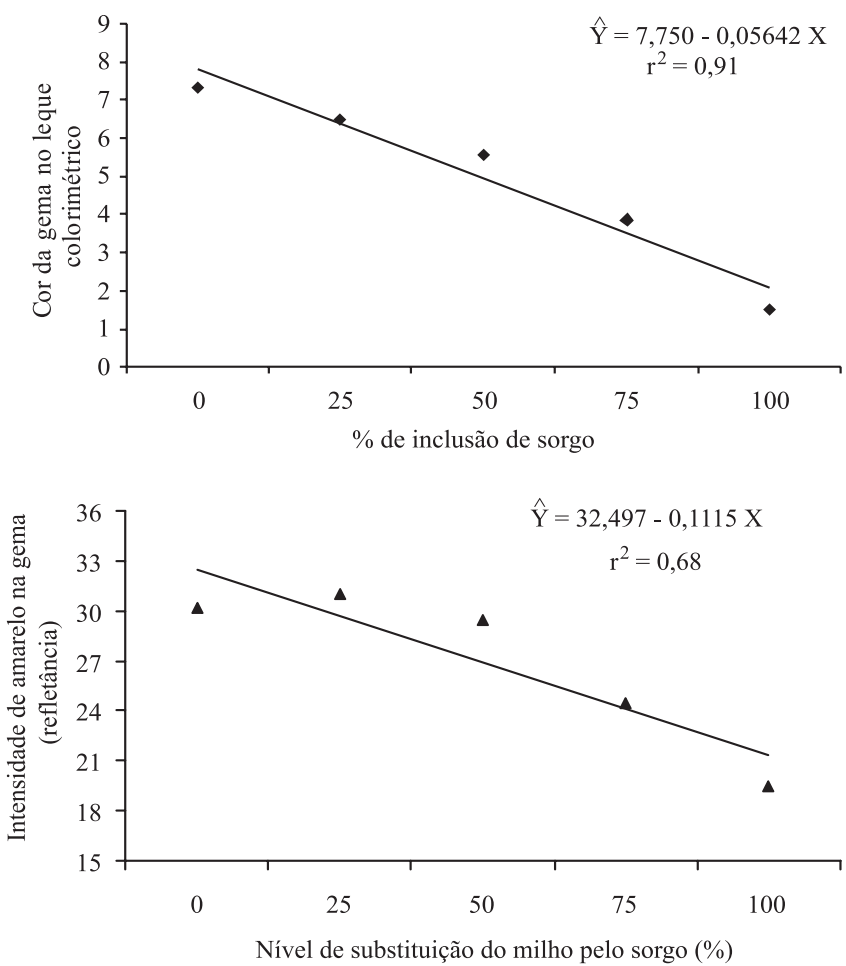

Figura 1 - Intensidade do amarelo na cor da gema dos ovos em função do nível de sorgo na ração utilizando escore colorimétrico DSM(A) e colorimetria por refletância(B). colorimétrico DSM (Figura 1) e pelo colorímetro Minolta (Figura 2).

Existem alternativas para pigmentar gemas dos ovos, como os pigmentantes naturais (Oliveira et al., 2007) e sintéticos (Garcia et al., 2002), todavia, a escolha da fonte e o nível de inclusão do pigmentante deve ser avaliada criteriosamente sob o aspecto econômico e mercadológico. $\mathrm{O}$ uso inadequado de pigmentantes exógenos pode inviabilizar a utilização do sorgo em rações para codornas em postura devido ao elevado custo, conforme destacado por Moreno et al. (2007).

A cor da gema é um critério de avaliação de qualidade pelo consumidor ou indústria. Entretanto, o ovo de codorna geralmente é consumido cozido e inteiro, ao contrário do ovo de galinha, que é submetido à cocção, fritura ou processamento pela indústria alimentícia. Isso torna a cor da gema do ovo de codorna um atributo de importância econômica secundária ou de pouca relevância.

Neste trabalho, inclusões crescentes de sorgo nas rações promoveram redução nos custos das formulações. A diferença entre o custo, por tonelada, da ração-referência (R $\$ 705,00)$ e a ração com $100 \%$ de substituição do milho pelo sorgo ( $R \$ 701,00)$ foi de $R \$ 4,00$. Essa diferença é representativa se considerado o volume de ração produzida anualmente para fomento da atividade. O preço do sorgo foi em torno de $25 \%$ inferior ao custo do milho, logo relações de custo entre o milho e o sorgo inferiores a $20 \%$ podem inviabilizar a substituição total do milho pelo sorgo, devido à necessidade de inclusão de aminoácidos sintéticos e de óleo vegetal para corrigir o perfil nutricional do sorgo.

Santos et al. (2006) realizaram uma análise econômica para verificar a viabilidade econômica da substituição do milho pelo sorgo para frangos de corte e notaram variação no custo por quilo de peso vivo, um indicativo de que o menor custo de produção ocorreu no lote das aves alimentadas com as dietas inicial e final contendo $50 \%$ de sorgo em substituição ao milho.

Como não foram evidenciadas diferenças significativas nos aspectos produtivos e de qualidade do ovo (à exceção da cor da gema), o critério econômico é decisório para a utilização do sorgo na coturnicultura de postura. De acordo com os resultados, tanto do aspecto nutricional quanto econômico, é viável a substituição total do milho pelo sorgo em rações para codornas japonesas em postura.

\section{Conclusões}

O sorgo contendo baixo tanino pode substituir totalmente o milho em rações para codornas japonesas em postura. A substituição é economicamente viável e não 
compromete os índices zootécnicos, no entanto, o aumento dos níveis de sorgo nas rações ocasiona redução na cor da gema. Desse modo, a inclusão de pigmentantes na ração deverá ser avaliada sob o aspecto econômico e mercadológico.

\section{Agradecimentos}

Ao Willian Fujikura da Granja Fujikura pela doação das codornas; à Empresa Pernambucana de Pesquisas Agropecuária (IPA) pela doação do sorgo; ao pesquisador José Milton Tabosa (IPA), aos professores Humberto Pena Couto (UENF), Vera Lúcia Arroxelas Galvão de Lima e Enayde de Almeida Melo (UFRPE) e aos estudantes de graduação da UFRPE Priscila Antão, Guilherme Rodrigues do Nascimento, Almir Ferreira da Silva e Quésia Jemima pelos auxílio e dedicação à pesquisa.

\section{Referências}

ASSUENA, V.; FILARDI, R.S.; JUNQUEIRA, O.M. et al. Substituição do milho pelo sorgo em rações para poedeiras comerciais formuladas com diferentes critérios de atendimento das exigências em aminoácidos. Ciência Animal Brasileira, v.9, p.93-99, 2008.

BARRETO, S.L.T.; PEREIRA, C.A.; UMIGI, R.T. et al. Determinação da exigência nutricional de cálcio de codornas japonesas na fase inicial do ciclo de produção. Revista Brasileira de Zootecnia, v.36, n.1, p.68-78, 2007.

BIBLE, B.B.; SINGHA, S. Canopy position influences cielab coordinates of peach color. Hortscience, v.28, n.10, p.992-993, 1997.

FAQUINEllo, P.; MURAKAM, A.E.; CELlA, P.S. et al. Hight tannin sorghum in diets of Japanese Quail (Coturnix coturnix japonica). Revista Brasileira de Ciência Avícola, v.6, p. 81-86, 2004

GALOBART, J.; SALA, R.; RINCO, X. et al. Egg yolk color as affected by saponiûcation of different natural pigmenting sources. Journal Applied of Poultry Research, v.13, p.328-334, 2004.

GARCIA, E.A; MENDES, A.A.; PIZZOLANTE, C.C. et al. Efeito dos níveis de cantaxantina na dieta sobre o desempenho e qualidade dos ovos de poedeiras comerciais. Revista Brasileira de Ciência Avícola, v.4, p.1-7, 2002.

MORENO, J.O.; ESPINDOLA, G.B.; SANTOS, M.S.V. et al. Desempenho e qualidade dos ovos de poedeiras comerciais, alimentadas com dietas contendo sorgo e páprica em substituição ao milho. Acta Scientiarum.Animal Sciences, v.29, p.159-163, 2007.

MOURA, A.M.A.; OLIVEIRA, N.T.E.; THIEBAUT, J.T.L. et al Efeito da temperatura de estocagem e do tipo de embalagem sobre a qualidade de ovos de codornas japonesas (Coturnix japonica). Ciência e Agrotecnologia, v.32, p.578-583, 2008.

MOURA, A.M.A.; FONSECA, J.B.; TAKATA, F.N. et al Determinação da energia metabolizável de alimentos para codornas japonesas em postura. Arquivo Brasileiro Medicina Veterinária e Zootecnia, v.62, n.1, p.178-183, 2010 .

NORDSTROM, J.O.; OUSTERHOUT, L.E. Estimation of shell weight and shell thickness from egg specific gravity and egg weight. Poultry Science Journal, v.61, p.1991-1995, 1982.

NATIONAL RESEARCH COUNCIL - NRC. Nutrient requirements of poultry. 9.ed. Washington, D.C.: National Academy of Sciences: 1994. 155p.

OLIVEIRA, A.M.; FURLAN, A.C.; MURAKAMI, A.E. et al Exigência nutricional de lisina para codornas japonesas (Coturnix coturnix japonica) em postura. Revista Brasileira de Zootecnia, v.28, n.5, p.1050-1053, 1999.

OLIVEIRA, N.T.E.; FONSECA, J.B.; SOARES, R.T.R.N. et al. Determinação da energia metabolizável de diferentes alimentos testados em codornas japonesas fêmeas. Arquivo Brasileiro Medicina Veterinária e Zootecnia, v.59, n.1, p.210-217, 2007.

ROCHA, V.R.R.A.; DUTRA JR., W.M.; RABELLO, C.B.V. et al. Substituição total do milho por sorgo e óleo de abatedouro avícola em dietas para frangos de corte. Revista Brasileira Zootecnia, v.37, n.1, p.95-102, 2008.

ROSTAGNO, H.S.; ALBINO, L.F.T.; DONZELE, J.L. et al. Tabelas brasileiras para aves e suínos: composição de alimentos e exigências nutricionais. 2.ed. Viçosa, MG: UFV, DZO, 2005. 186p.

SANTOS, M.S.V.; ESPÍNDOLA, G.B.; FUENTES, M.F.F. Utilização de complexo enzimático em dietas à base de sorgosoja para frangos de corte. Revista Brasileira de Zootecnia v.35, n.3, p.811-817, 2006.

SILVA, D.J.; QUEIROZ, A.C. Análise de alimentos: métodos químicos e biológicos. 3.ed. Viçosa, MG: UFV, 2002. 235p.

SILVA, J.H.V.; ALBINO, L.F.T.; GODÓI, M.J.S. Efeito do extrato de urucum na pigmentação da gema dos ovos. Revista Brasileira de Zootecnia, v.29, n.5, p.1435-1439, 2000.

SCHEUERMANN, N.G. Utilização do sorgo em rações para frangos de corte. Avicultura Industrial, n.11, 1107 (94), p.95-96, 2003.

TEMMINCK, C.; SCHLEGEL, H. Description des oiseaux observés au Japon par les voyageurs Hollandais. In: von SIEBOLD, P.F. (Ed.). Oiseaux. Paris: 1849. 227p.

UNIVERSIDADE FEDERAL DE VIÇOSA - UFV. Sistema de Análises Estatísticas e Genéticas - SAEG. Versão 9.1. Viçosa, MG, 2007. (CD-ROM). 